\title{
Upload Filters and the EU Copyright Reform
}

\author{
Axel Nordemann
}

Published online: 6 March 2019

(C) Max Planck Institute for Innovation and Competition, Munich 2019

The amendments adopted by the European Parliament on 12 September 2018 on the proposal for a Directive of the European Parliament and of the Council on copyright in the Digital Single Market, have substantially weakened Arts. 13 to $13 \mathrm{~b}$ in favour of content providers such as Google and YouTube. Initially, Art. 13 held such providers liable to take down content uploaded by users if it infringes copyright. It was also proposed that service providers must supply rightholders with adequate information on the functioning and the deployment of the measures, as well as, when relevant, adequate reporting on the recognition and use of the works and other subject-matter. Service providers should also put in place complaints and redress procedures, which are available to users in cases of disputes over the application of such measures. The actions furthermore needed to include effective content recognition technologies. This was removed through the latest amendment as the result of intensive lobbying by Google, and user as well as consumer associations. It was replaced by a watered-down rule no longer containing any effective measures for a "notice and stay down", instead referring to fundamental rights, the use of exceptions and limitations as well as stressing that the burden on SMEs had to remain appropriate and that automated blocking of content is to be avoided. Furthermore, Art. 13 now begins with a suggestion that service providers should conclude fair and appropriate licensing agreements with right holders.

Sadly, it must be said that Art. 13 in the form in which it entered the Trilogue talks, starts with a bang in the first paragraph but ends with a whimper in the

Axel Nordemann is an Honorary Professor at the University of Constance (Constance, Germany) and a Partner at Boehmert \& Boehmert, Berlin. Note that this Editorial was finalized in December 2018. However, on February 13, 2019, the Trilogue negotiations were concluded with a new proposal for an amended text of Art. 13.

A. Nordemann $(\bowtie)$

Dr. jur.; Berlin, Germany

e-mail: a.nordemann@boehmert.de 
paragraphs thereafter. What use is a declaration that calls upon services which do not act neutrally, such as YouTube, to conclude fair and appropriate licensing agreements with rightholders if no clear rules are laid out for those situations where this does not occur or if the parties concerned cannot agree on the appropriate conditions? The result is that the current draft directive does not place any obligations on neutral platform services such as YouTube that were not already applicable under existing law prior to the legislative initiative. The fact that the licensing agreement at the platform level will also benefit the individual users is nice to read (again in the form of a declaration) as a sentiment; however, this would have been the case anyway without the explicit mention. The major record labels concluded licensing agreements with YouTube years ago, which as a matter of fact also covered YouTube users.

In the debates on the topic of the "value gap" or "liability exemptions", the major platform operators, above all Google and YouTube, stressed time and again that they were not able to identify whether users posted illegal content on their platform or not. According to them, they of course have no interest in adopting such content as their own; rather, even if they played an "active role", they would at most be a neutral distributor, for whom it would be appropriate to relieve their liability. Most participants in the debate have clearly forgotten that this would be no different for completely normal participants in a marketplace involving protected content. Hence, it is worth stating by way of reminder what the "normal" liability concept for such cases looks like: a mere distributor who unknowingly and unwillingly participates in a copyright infringement, still has a liability towards the rightholder and is obligated to seek recourse from the supplier responsible for the illegal content. The logic is therefore that the injured party obtains compensation from the distribution platform and does not bear the risk of the party actually responsible for the infringement being unable to pay. Why is that? Because the platform operator attracted its users and not the injured party. It is precisely this rationale for the normal distribution of risk that is constantly overlooked in discussions involving Art. 13 of the Copyright Directive. It goes without saying that the rules for online retailers also apply to all publishers or record producers in Germany, in particular, in not so uncommon distribution agreements. Should that not also apply to YouTube? If YouTube is the subject of legal action for damages, it can recoup the money from the users. Is that not possible? Admittedly, this would require a viable licensing tool. Even if YouTube would eventually conclude umbrella agreements of the kind the current draft proposes, this would be subsequent to negotiations on a level playing field. After all, anyone who uploads something to YouTube must conclude a user agreement in which they promise to observe third-party copyright.

One of the greatest PR victories for the Google and YouTube lobby has been to use a clever act of political framing to rid themselves, through the amendment, of the accepted and wholly uncontroversial legal principle of "notice and stay down", as first formulated by the European Court in its L'Oreal decision (judgment of 12 July 2011, case No. C-324/09 - L'Oréal v. eBay). To this end, the exact same concept has been re-coined as "upload-filters", suggesting a new, hitherto unknown obligation was to be imposed. In the L'Oreal decision, the CJEU clarified that 
Member States must ensure effective protection of intellectual property which includes "to order an online service provider, such as a provider making an online marketplace available to internet users, to take measures that contribute not only to bringing to an end infringements committed through that marketplace, but also to preventing further infringements" (p. 131). This is nothing else but the kind of tool Google and others have now started to call an "upload-filter", which eBay had to install to prevent future infringements after receipt of a notice and take down letter back in 2011 !

Finally, we should not forget that copyright is irrefutably necessary to protect the interests of the authors and their contractual partners. Creativity will suffer, if we do not protect the intellectual property of those creating the content in a sufficient and effective way. If creating content is no longer lucrative, then there will no longer be sufficient content to be uploaded. And we should keep in mind that providers like Google and YouTube earn billions each year, largely because they provide platforms to upload content created by third parties; they should pay a fair compensation to ensure that content is still created in the future, and take on the burden of ensuring that once they have been made aware of an infringement that the infringing content stays down in the future.

Publisher's Note Springer Nature remains neutral with regard to jurisdictional claims in published maps and institutional affiliations. 